\title{
Booking the cooks
}

\section{Kenneth Mellanby}

But the Crackling is Superb: An Anthology on Food and Drink by Fellows and Foreign Members of the Royal Society. Edited by Nicholas and Giana Kurti. Adam Hilger: 1988. Pp.261. £12.50. Available in the United States from Taylor \& Francis Inc., \$29.

Professor Nicholas Kurti, an authority on low-temperature physics, deserves our condolences, in that for his new anthology of kitchen hints he has failed to goad his distinguished fellow contributors to reach his own high standard of amiable culinary eccentricity.

In recent years, the fashion has grown up of what one might call 'instant books'. You wish to compile a book on dogs so you write to a large number of well-known people asking about their pets. A few reply and hey presto! you have a bestseller. This is a variant of the technique of standing in a shopping mall with pencil and notebook asking people impertinent questions about their sex lives, their religion or their choice of the best household detergent. Alas, these approaches seldom produce a genuine book of value or coherence - But the Crackling is Superb is no exception.

What is rather perplexing is that Professor Kurti's gathering ground was so fertile. He wrote to several hundred fellows of the Royal Society - the cream of Britain's scientific intelligentsia asking for recipes or food advice, but one really has to admit the results do not bolster anyone's reputation. If a distinguished physicist can produce a recipe of such monumental imprecision as at least one of the pieces in this book, one finds oneself wondering what his scientific experiments can be like. No editor of Women's Institute anthology, or of a village collection of local recipes, could pass by contributions that are so inexact, or commonplace, or both.

Unsurprisingly, Professor Kurti's own contributions combine expertise with innovation. There certainly is a place for science in the kitchen, and he leaves us with a delightful picture of himself sticking several thermometers into a soufflé. I personally admire his creative approach and share his enthusiasm. In years gone by my interests as given in Who's Who included wine and food, until advancing years, a lowered capacity for intake and, above all, growing awareness of ecological constraints, obliged me to change the entry into "austere living".

So instead of passing learned comments on food and drink I now shall have recourse to yet another technique for producing instant books - that is, anthologizing from anthologies. I rather like a quotation from Lord Horder, once medical adviser to Britain's royal family:

Our bodies are not puritanical. The pleasant habits of eating and drinking were never meant to be subject to a chemical equation

Perhaps Professor Kurti would disagree, and prefer the surgeon Sir Robert Hutchinson:

Vegetarianism is harmless enough, though it is apt to fill a man with wind and self-righteousness.

Kurti is certainly not a vegetarian. Let us try Magnus Pyke, probably Britain's best- known nutritionist:

Meat is a status dish in which the sizzle counts for more than the intrinsic nutritional worth

But as a staunch ecologist I would finally echo another piece of wisdom from Magnus Pyke:

We are wealthy and wasteful but this can't go on. If we don't eat dog biscuits, we could end up eating our dogs instead.

Kenneth Mellanby, 38 Warkworth Street, Cambridge CBI IEG, UK, is a keen cook and is author of Can Britain Feed Itself? (1975).

\section{New angles on momentum}

\section{R. N. Dixon}

Angular Momentum: Understanding Spatial Aspects in Chemistry and Physics. By Richard N. Zare. Wiley:1988. Pp.349. $\$ 39.95, £ 34.50$.

WE ARE all familiar with phenomena that are related to angular momentum: that a bicycle at speed does not readily fall over, and that the currents in the oceans of the rotating Earth tend to follow a circular motion. We also know that the electrons in an atom tend to revolve around the nucleus as in a miniature Solar System. Thus all chemistry and physics undergraduates learn of the importance of angular momentum quantum numbers in describing the motions of atoms and molecules. Even so, the mathematical description of angular momentum baffles most of us, not least because the formal examples usually found in textbooks seem so remote from practical application. Richard Zare's book is destined to change all that.

A fundamental aspect of the layout of the book is that the basic theory introduced in each chapter is put to use when the student solves the problems at the end of the chapter. These are no mere formal exercises: they illustrate how the theory works in explaining such widely different experiments as the anisotropy of the scattering of beams of atoms fired at one another, and the nuclear spin structure in the microwave spectrum of the $\mathrm{ClCN}$ molecule. In the words of the author, "for someone to read the text and skip the problem sets and applications is like someone reading a book on how to play the piano without ever sitting before a keyboard".

The book is intended for an American one-semester graduate course. It is equally appropriate for a graduate course in Britain, particularly for atomic physicists, physical chemists or chemists using spin-dependent analytical techniques such as magnetic resonance. It may even find a place in specialist courses in the final undergraduate year. It requires the student to have only a basic knowledge of quantum mechanics, and has the merit of leaving in many of the intermediate steps in the derivations.

Zare starts with the angular momentum of a single quantum particle, then generalizes the theory to two or more coupled angular momenta. Transformations under rotation are described in detail, and applied to separating the physical and dynamical parts of molecular problems from the angular or geometric parts. Applications include the polarization of fluorescence from rotating molecules, and quantum beats. This leads on to the energy-level structure and wave-functions of a rigid rotor. An appendix contains a FORTRAN listing of a program for calculating numerical values of all the angular coupling factors which appear in practical problems. The four problem sets and 16 applications make up one third of the length of the volume.

This is certainly not the first book on the theory of angular momentum, but it is the first to combine the basic theory with excellent illustrations of how that theory works across a wide range of topics in chemistry and physics. It will be widely used as a learning text for postgraduate students, and as a revision primer and reference work for their tutors.

$R$. N. Dixon is in the School of Chemistry, University of Bristol, Cantock's Close, Bristol BS8 ITS, UK

\section{New editions}

- Soil Physics, 2nd edn, by T. J. Marshall \& J. W. Holmes. Publisher is Cambridge University Press, price is hbk $£ 45, \$ 89.50$, pbk $£ 15 . \$ 29.95$. For review see Nature 289.731 (1981).

- Supercomputers and their Use, revised edn, by C. Lazou. Publisher is Oxford University Press, price is hbk $£ 25$, pbk $£ 12.50$. For review see Nature 326, 910 (1987)

- Pioneers of Science: Nobel Prize Winners in Physics, 2nd edn, by R. L. Weber. Publisher is Adam Hilger, price is $£ 12.95$.

- Ecotoxicology: The Study of Pollutants in Ecosystems, 2nd edn, by F. Moriarty. Publisher is Academic, price is Hbk $£ 22.50, \$ 44.50$, pbk $£ 10.95, \$ 23$. 